\title{
Evidence based medicine: flawed system but still the best we've got
}

\author{
Fiona Godlee editor, BMJ
}

Evidence based medicine is so much part of the air we breathe it can be hard to remember a time before it. An oral history, filmed for a joint $J A M A$ and $B M J$ celebration last year, has now been published on bmj.com/evidence and the JAMA network. As summarised in an editorial co-published by the two journals this week, the story features a satisfying array of heroes and detractors, forward progress and backlash (doi:10.1136/bmj. g371).

Why did evidence based medicine take off? In the video, and quoted in the editorial, David Sackett provides two main reasons: it was supported by senior clinicians who were secure in their practice and happy to be challenged, and it empowered younger doctors-and subsequently nurses and other clinicians- to question received wisdom and practice.

Sackett and his generation also succeeded because they were natural iconoclasts. And now that evidence based medicine is part of the medical establishment and is itself an icon, it's only right that it has become a target for the new iconoclasts. In a recent column Des Spence claimed that evidence based medicine was broken and that the research pond was polluted by fraud, sham diagnosis, short term data, poor regulation, surrogate endpoints, and clinically irrelevant outcomes (doi:10.1136/bmj. g22).

Spence said that evidence based medicine left no room for discretion and fuelled overdiagnosis and overtreatment. A good number of rapid responders agreed (http://bit.ly/1jkDFZ8), some even saying he didn't go far enough. Others defended the precepts of evidence based medicine and warned against throwing the baby out with the bathwater.

This week we highlight a story that could be used to argue either way. Rita Redberg and colleagues describe the saga of the Wingspan intracranial stenting device (doi:10.1136/bmj.g93). They tell us that its continued licensing and use in people with a previous stroke were based on a single, industry funded, uncontrolled study of 44 patients, while the only randomised trial showed clear evidence of increased deaths and strokes when the device was compared with medical treatment.

The Wingspan has been licensed under a special regulatory programme for high risk devices in rare conditions. In an accompanying commentary, Hwang and colleagues highlight the generally poor quality of the evidence for such devices, mainly small and uncontrolled studies (doi:10.1136/bmj.g217). Both sets of authors call for far greater regulatory scrutiny of the safety and effectiveness of medical devices.

As with democracy and peer review (with apologies to Winston Churchill), evidence based medicine may be the worst system for clinical decision making, except for all those other systems that have been tried from time to time. It is only as good as the evidence and the people making the decisions.

The $B M J$ s collection of resources on evidence based medicine is at bmj.com/evidence.

Cite this as: BMJ 2014;348:9440

๑ BMJ Publishing Group Ltd 2014 